\title{
Genetic Diversity of Salvia Species Assessed by ISSR and RAPD Markers
}

\author{
Masoumeh YOUSEFIAZARKHANIAN ${ }^{1 *}$, Ali ASGHARI ${ }^{1}$, \\ Jafar AHMADI ${ }^{2}$, Behvar ASGHARI ${ }^{2}$, Ali Ashraf JAFARI ${ }^{3}$ \\ ${ }^{1}$ University of Mohaghegh Ardabili, Faculty of Agricultural and Natural Resources, Daneshgah St. Ardabil, \\ Iran; mas.yousefiazar@yahoo.com ("correspondingauthor); ali_asgharii@yahoo.com \\ ${ }^{2}$ Imam Khomeini International University, Faculty of Agriculture and Natural Resources, Qazvin, \\ Iran; njahmadi910@yahoo.com; behvar.asghari@gmail.com \\ ${ }^{3}$ Research Institute of Forests and Rangelands, Agricultural Research Education and Extension Organization (AREEO), Tehran, \\ Iran; aliashrafj@gmail.com
}

\begin{abstract}
The genus Salvia includes an enormous assemblage of nearly 1,000 species dispersed around the world. Due to possible threats to this genus, there is an immediate requirement to evaluate the diversity of its wild populations. ISSR and RAPD molecular techniques were used to evaluate the genetic relationships among twenty-one ecotypes of eight Salvia species. Amplification of genomic DNA using 23 primers (15 RAPD and eight ISSR) produced 280 bands, of which $91 \%$ were polymorphic. The results of marker parameters showed no clear difference between two marker systems. It was generally observed that both ISSR and RAPD markers had similar efficiency in detecting genetic polymorphisms with remarkable ability to differentiate the closely related ecotypes of Salvia. Nei's similarity coefficients for these techniques ranged from 0.48 to 0.98 . Based on the results of clustering, PCoA and AMOVA, the genetic diversity between and within species was confirmed. So, conservation and domestication of the genus Salvia must be due to levels of genetic variations.
\end{abstract}

Keywords: AMOVA, Clustering, Marker parameters, PCoA, Polymorphism

\section{Introduction}

The genus Salvia (tribe Mentheae, Lamiaceae) includes an enormous assemblage of nearly 1,000 species displaying a notable range of variation around the world: Central and South America (500 spp.), central Asia/Mediterranean (250 spp.), and eastern Asia (90 spp.) (Erbano et al., 2015). Exploitation of the genus Salvia has been widely increased in the industries such as pharmaceutical, food and spices production (Wang et al., 2011). Additionally, the abundance of metabolites as principal chemical components in Salvia species, gives them distinctive pharmacological specifications including, anti-inflammatory, antiplatelet and antithrombotic effects (Erbano et al., 2015). Salvia has also been used to treat a number of different diseases such as acquired immunodeficiency syndrome (AIDS), diabetes, liver malfunction and Alzheimer's disease (Sepehry Javan et al., 2012).

Sepehry Javan et al. (2012) mentioned that three major factors influencing genetic variations in Salvia are: species, geographical distribution and selection. These factors along with cross-pollination make the taxonomy and genetic relationships of Salvia species unclear (Wang et al., 2011). Morphological characteristics are easily affected by environment that makes identification of species more complex (Chen et al., 2013). The conservation and suitable use of plant genetic resources require accurate monitoring of their accessions. So, genetic characterization is essential to manifest the extent of plant genetic diversity, and also to discover better genotypes; especially in the geographically differentiated genus such as Salvia (Song et al., 2010; Peng et al., 2014). In the era of modern biotechnology, several DNA-based molecular markers have been developed either for cultivar identification or assessment of genetic relationships among plant species. These techniques include properties like cost effectiveness, abundance, stability, high polymorphism and independency from environmental influences (Kharazian et al., 2015).

RAPD markers provide a convenient tool for studying genetic differences even at lower intraspecific levels.. Inter-Simple Sequence Repeat-Polymerase Chain Reaction (ISSR-PCR) technique is an efficient system for identification of plant genetic diversity. It is also suitable to address evolutionary processes at inter- and intra-specific level (Peng et al., 2014; Kharazian et al., 2015). This technique involves primers composed of a microsatellite sequence anchored at $3^{\prime}$ or $5^{\prime}$ ends by $2-4$ arbitrary nucleotides and higher annealing temperatures. Also, ISSRs are easier to use due to their reproducibility; but they differentiate mostly as dominant following simple Mendelian inheritance like RAPDs (Song et al., 2010). 
Table 1. Identity of Salvia species used for genetic diversity analysis

\begin{tabular}{|c|c|c|c|c|c|c|}
\hline Scientific name & Abbreviation & Collection site & State & Latitude & Longitude & Altitude (m) \\
\hline \multirow{3}{*}{ Salvia aethiopis } & $\mathrm{AJ}$ & Jadeh Chalous & Mazandaran & $36^{\circ} 22^{\prime} 12^{\prime \prime} \mathrm{N}$ & $51^{\circ} 07^{\prime} 12^{\prime \prime} \mathrm{W}$ & 1200 \\
\hline & AR & Roudbar & Gilan & $36^{\circ} 47^{\prime} 06^{\prime \prime} \mathrm{N}$ & $49^{\circ} 49^{\prime} 52^{\prime \prime} \mathrm{W}$ & 1880 \\
\hline & $\mathrm{AK}$ & Khalkhal & Ardabil & $37^{\circ} 38^{\prime} 53^{\prime \prime} \mathrm{N}$ & $48^{\circ} 36^{\prime} 11^{\prime \prime} \mathrm{W}$ & 1958 \\
\hline \multirow{3}{*}{ Salvia macrosiphon } & MK & Khatam & Yazd & $30^{\circ} 07^{\prime} 24^{\prime \prime} \mathrm{N}$ & $53^{\circ} 59^{\prime} 06^{\prime \prime} \mathrm{W}$ & 2178 \\
\hline & MD & Dashtestan & Boushehr & $28^{\circ} 57^{\prime} 22^{\prime \prime} \mathrm{N}$ & $51^{\circ} 28^{\prime} 31^{\prime \prime} \mathrm{W}$ & 430 \\
\hline & MJ & Jahrom & Fars & $29^{\circ} 20^{\prime} 07^{\prime \prime} \mathrm{N}$ & $51^{\circ} 52^{\prime} 08^{\prime \prime} \mathrm{W}$ & 1610 \\
\hline \multirow{3}{*}{ Salvia nemorosa } & NI & Khansar & Isfahan & $33^{\circ} 10^{\prime} 00^{\prime \prime} \mathrm{N}$ & $50^{\circ} 23^{\prime} 00^{\prime \prime} \mathrm{W}$ & 2400 \\
\hline & NK & Khalkhal & Ardabil & $37^{\circ} 39^{\prime} 51^{\prime \prime} \mathrm{N}$ & $48^{\circ} 18^{\prime} 55^{\prime \prime W}$ & 1782 \\
\hline & NQ & Qazvin & Qazvin & $36^{\circ} 33^{\prime} 36^{\prime \prime} \mathrm{N}$ & $50^{\circ} 26^{\prime} 20^{\prime \prime} \mathrm{W}$ & 2250 \\
\hline \multirow{2}{*}{ Salvia officinalis } & $\mathrm{OH}$ & Hamedan & Hamedan & $34^{\circ} 46^{\prime} 10^{\prime \prime} \mathrm{N}$ & $48^{\circ} 30^{\prime} 00^{\prime \prime} \mathrm{W}$ & 1870 \\
\hline & ON & Najafabad & Isfahan & $32^{\circ} 36^{\prime} 93^{\prime \prime} \mathrm{N}$ & $51^{\circ} 27^{\prime} 90^{\prime \prime} \mathrm{W}$ & 1642 \\
\hline \multirow[b]{2}{*}{ Salvia reuterana } & RK & Khoramabad & Lorestan & $33^{\circ} 29^{\prime} 07^{\prime \prime} \mathrm{N}$ & $48^{\circ} 22^{\prime} 12^{\prime \prime} \mathrm{W}$ & 2040 \\
\hline & RT & Tehran & Tehran & $35^{\circ} 43^{\prime} 41^{\prime \prime} \mathrm{N}$ & $51^{\circ} 35^{\prime} 32^{\prime \prime} \mathrm{W}$ & 1618 \\
\hline \multirow{3}{*}{ Salvia sclarea } & SR & Rostamabad & Gilan & $36^{\circ} 55^{\prime} 10^{\prime \prime} \mathrm{N}$ & $49^{\circ} 24^{\prime} 30^{\prime \prime} \mathrm{W}$ & 1290 \\
\hline & SM & Meshkinshahr & Ardabil & $36^{\circ} 21^{\prime} 12^{\prime \prime} \mathrm{N}$ & $48^{\circ} 14^{\prime} 28^{\prime \prime} \mathrm{W}$ & 1260 \\
\hline & $S Q$ & Qazvin & Qazvin & $36^{\circ} 33^{\prime} 89^{\prime \prime} \mathrm{N}$ & $50^{\circ} 18^{\prime} 70^{\prime \prime} \mathrm{W}$ & 2100 \\
\hline \multirow{2}{*}{ Salvia verticillata } & $\mathrm{VQ}$ & Qazvin & Qazvin & $36^{\circ} 22^{\prime} 34^{\prime \prime} \mathrm{N}$ & $50^{\circ} 32^{\prime} 19^{\prime \prime} \mathrm{W}$ & 1836 \\
\hline & $\mathrm{VK}$ & Karaj & Tehran & $35^{\circ} 58^{\prime} 11^{\prime \prime} \mathrm{N}$ & $51^{\circ} 21^{\prime} 15^{\prime \prime W}$ & 2170 \\
\hline \multirow{3}{*}{ Salvia virgata } & $\mathrm{ViJ}$ & Jadeh Chalous & Mazandaran & $36^{\circ} 22^{\prime} 12^{\prime \prime} \mathrm{N}$ & $51^{\circ} 07^{\prime} 12^{\prime \prime} \mathrm{W}$ & 1200 \\
\hline & $\mathrm{ViN}$ & Najafabad & Isfahan & $32^{\circ} 36^{\prime} 93^{\prime \prime} \mathrm{N}$ & $51^{\circ} 27^{\prime} 90^{\prime \prime} \mathrm{W}$ & 1642 \\
\hline & $\mathrm{ViQ}$ & Qazvin & Qazvin & $36^{\circ} 33^{\prime} 36^{\prime \prime} \mathrm{N}$ & $51^{\circ} 26^{\prime} 20^{\prime \prime} \mathrm{W}$ & 2250 \\
\hline
\end{tabular}

Plant genetic diversity is an important factor for their domestication and breeding. Accordingly, some researchers have tried to assess this variability by ISSR and RAPD techniques in different Salvia species (Song et al., 2010; Wang et al., 2011; Sepehry Javan et al., 2012; Zhang et al., 2013; Peng et al., 2014; Erbano et al., 2015). Genetic variability was also investigated in a genus of Lamiacea family as Ocimum, with the application of these markers (Chen et al., 2013; Patel et al., 2014). Germplasm variation detected by ISSRs has been reported in the genus Stachys, due to the rich genetic resources of the collection regions; which are important in conservation purposes (Kharazian et al., 2015).

Given the possible threats to Iran's natural landscapes; where Salvia is one of the threatened component genera, there is an immediate requirement to evaluate the diversity of wild populations, especially those with economic values. The present research was undertaken with the aims of evaluating the genetic diversity of the eight species of Salvia.

\section{Materials and Methods}

\section{Plantmaterials}

Twenty-one ecotypes of eight Salvia species were selected from different geographical regions of Iran (Table 1). The seeds of these ecotypes were provided by the Gene Bank of Iran, Research Institute of Forest and Rangelands; and sowed in a greenhouse for sampling.

\section{Isolation and evaluation of the quantity/quality of genomic DNA}

Young leaves of each ecotype were ground as bulk into a fine powder in liquid nitrogen. Powders (250 mg) were immediately transferred to a tube adding $1 \mathrm{ml}$ of preheated extraction buffer [2\% CTAB, $100 \mathrm{mM}$ Tris- $\mathrm{HCl}(\mathrm{pH}=8), 25$ mM EDTA $(\mathrm{pH}=8), 2.5 \mathrm{M} \mathrm{NaCl}, 2 \%$ polyvinylpyrrolidone (PVP), and $1 \% \beta$-mercaptoethanol]. The mixture was shaken and incubated at $65^{\circ} \mathrm{C}$ for $1 \mathrm{~h}$ in a water bath. Then the tubes were centrifuged at $9,720 \mathrm{rcf}$ for $10 \mathrm{~min}$ at $4{ }^{\circ} \mathrm{C}$ and the transparent upper phase was transferred into a fresh tube. An equal volume of chlorophorm : isoamyl alcohol (24:1) was added and mixed slowly. Samples were centrifuged at 9,720 rcf for 10 min at $4{ }^{\circ} \mathrm{C}$ and the aqueous phase was transferred into a new tube. Isopropanol was added to precipitate nucleic acids; tubes were shaken and incubated at $-20{ }^{\circ} \mathrm{C}$ for $30 \mathrm{~min}$. Precipitated DNA was centrifuged at $19,000 \mathrm{rcf}$ for $10 \mathrm{~min}$ at $4{ }^{\circ} \mathrm{C}$ and supernatant was removed. DNA pellets were washed with $500 \mu \mathrm{l}$ of $70 \%$ ethanol. The DNA pellets were dried and dissolved in $200 \mu \mathrm{l}$ TE buffer [10 mM Tris-HCl (pH 8.0), 1 mM EDTA ( $\mathrm{pH} 8.0)]$. The quality and quantity of the DNAs were evaluated by $0.8 \%$ agarose gel and NanoDrop Spectrophotometer.

\section{PCR amplification}

A set of 13 ISSR primers from UBC Company (the University of British Columbia), and 30 decamer RAPD primers from Operon Technologies Inc. (USA) were screened for their repeatable amplification (Table 1). For each primer, Polymerase Chain Reaction (PCR) in volume $25 \mu$ was composed of Taq DNA polymerase enzyme $(1 \mathrm{u} / \mu \mathrm{l})$, PCR $\operatorname{Buffer}(1 \mathrm{X}), \operatorname{Mgcl}_{2}(2 \mathrm{mM}), \mathrm{dNTP}(200 \mu \mathrm{M})$, primer $(0.5 \mu \mathrm{M})$, DNA (50 ngr) and $\mathrm{ddH}_{2} \mathrm{O}$. Amplifications were carried out using a DNA thermal cycler (Tech Model TC-5000) with the following program: initial denaturation for $3 \mathrm{~min}$ at $95^{\circ} \mathrm{C}$ followed by 35 cycles of denaturation for 30 s at $95^{\circ} \mathrm{C}$, annealing of $30 \mathrm{~s}$ at $34^{\circ} \mathrm{C}$ for RAPD and at $30-43^{\circ} \mathrm{C}$ for ISSR, extension at $72^{\circ} \mathrm{C}$ for $2 \mathrm{~min}$, and final elongation at $72^{\circ} \mathrm{C}$ for $10 \mathrm{~min}$. Each amplified PCR products (in three replications), were run on $1.5 \%$ agarose gel visualized by ethidium bromide staining, and the images were documented using Gel Documentation System (USA) under U.V. lights.

\section{Statistical analysis}

Reproducible patterns of each ISSR and RAPD primers were selected for manual band scoring as ' 0 ' (no band) and ' 1 ' (presence of band) binary data matrix. Number of total loci (TB), number of polymorphic loci (PB) and polymorphism percentage $(\mathrm{PPB} \%)$ were calculated for each primer. The suitability of both the ISSR and RAPD markers to evaluate genetic profiles of Salvia ecotypes was measured using these parameters: Polymorphism index (PI) and Polymorphism Information Content (PIC) were calculated as explained by Rizza et al. (2007). Effective Multiplex Ratio or $E M R=n \times P P B \%$; where $\mathrm{n}$ is the average number of fragments amplified by 
accessions, and Marker Index $(M I=P I C \times \mathrm{EMR})$ were estimated to characterize the capacity of each primer to detect polymorphic loci among the genotypes (Powell et al., 1996). Also, the Resolving Power (RP) of each primer was scored by $R P=\sum I b$; where $\mathrm{Ib}$ represents the informative fragments as $I b=1-\left(2 \times\left|0.5-p_{i}\right|\right)$ (Chen et al., 2013). Simpson's Index was evaluated based on Manica-Cattani et al. (2009) as $S I=\sum\left(1-p_{i}^{2}\right) / \mathrm{N}$. In latter equations, $\mathrm{p}_{\mathrm{i}}$ is the frequency of the $\mathrm{i}^{\mathrm{th}}$ allele, and $\mathrm{N}$ is the number of polymorphic loci detected by each primer. The data matrix was submitted to determine observed number of alleles $\left(\mathrm{N}_{\mathrm{o}}\right)$, expected number of alleles $\left(\mathrm{N}_{\mathrm{e}}\right)$, Nei's gene diversity $(\mathrm{h})$, Shannon's information index of genetic diversity $(\mathrm{I})$, total heterozygosity $\left(\mathrm{H}_{\mathrm{t}}\right)$, average heterozygosity within populations $\left(\mathrm{H}_{\mathrm{s}}\right)$, degree of genetic differentiation for polymorphism between populations $\left(\mathrm{G}_{\mathrm{st}}\right)$ and indirect estimation of gene flow between populations $\left(\mathrm{N}_{\mathrm{m}}\right)$ using the software POPGENE ver. 1.32. The data matrix of both markers was converted into genetic similarity matrix using pairwise Nei's unbiased genetic distance (Nei, 1978). The genetic relatedness among the ecotypes and species was analyzed by an unweighted pair group method with arithmetic average (UPGMA) using TFPGA software, and related dendrograms were constructed by resampling with 1,000 replacements over loci. Bootstrap values were considered as a frequency to form a particular group. Analysis of Molecular Variance (AMOVA) was used to calculate variation among and within population using GenAlEx 6.501 ver. 6.41. As well, Principal Coordinate Analysis (PCoA) was performed using GenAlEx to highlight the resolving power of the ordination based on similarity coefficients. Mantel test was performed using 1,000 permutations in XLSTAT, 2015 software $(\alpha=0.05)$, to compute the correlation $(r)$ between the similarity matrices to test the congruence of fit between RAPD and ISSR markers.

\section{Results}

\section{ISSR analysis}

The total numbers of amplified fragments generated by eight ISSRs were 98, with sizes ranging from 300 to 3,000 bp. All $85(86.7 \%)$ loci were polymorphic (Fig. 3-a, Table 2). The minimum number of amplified bands (TB) as well the smallest number of polymorph loci (PB) were both obtained with UBC-825 (10 and 8, respectively). As well, the maximum number of TB and PB were recorded for UBC-823 (14 and 13 , respectively). The averages of 12 and 10 loci per primer were obtained for TB and PB, respectively. The percentage of polymorphism (PPB) varied from $77 \%$ for UBC-841-Y to 93\% for UBC-823 (Table 2). High PIC value of 0.46 (UBC855 ) and low PIC value of 0.38 (UBC-846), with an average value of PIC per primer 0.43 were obtained. In this experiment, the highest effective multiplex ratio (EMR, 11.14) was observed with the primer UBC-823 and the lowest amount of this ratio (7.16) was detected by the primer UBC-873 with an average EMR of 8.49 per primer. The highest value of marker index (MI) was recorded with the primer UBC-823 as 5.1 and the lowest MI was observed in the primer UBC-846 as 2.8, totally with an average of MI per primer that was calculated as 3.7. The highest resolving power (RP) value was for the primer UBC-823 (10.0), and the lowest RP observed by UBC-825 as 5.3 with an average RP of 7.4 per primer. The most values of Simpson's index were for UBC-873 (SI=0.80), while the lowest value of this index was 0.66 for UBC-823 (Table 2). The Nei's gene diversity (h) and Shannon index (I) among all studied ecotypes of Salvia about ISSR marker data were calculated as $0.37 \pm 0.16$ and $0.53 \pm 0.22$, respectively. Mean coefficient of gene differentiation $\left(\mathrm{G}_{\mathrm{st}}\right)$ was found as 0.80 , while the estimation of gene flow $\left(\mathrm{N}_{\mathrm{m}}\right)$ in the population was 0.12 (Table 3 ). The

Table 2. Marker parameters calculated for each tested primer among Salvia ecotypes

\begin{tabular}{|c|c|c|c|c|c|c|c|c|c|c|}
\hline Locus name & Sequence 5'-3' & TB & $\mathrm{PB}$ & PPB (\%) & PI & PIC & EMR & MI & $\mathrm{RP}$ & SI \\
\hline UBC-823 & (TC)8C & 14 & 13 & 93 & 5.91 & 0.455 & 11.14 & 5.07 & 10.00 & 0.66 \\
\hline UBC- 825 & (AC) $8 \mathrm{~T}$ & 10 & 8 & 80 & 3.40 & 0.425 & 7.50 & 3.19 & 5.33 & 0.77 \\
\hline UBC-841-Y & (GA)8YC & 13 & 10 & 77 & 4.21 & 0.421 & 7.46 & 3.14 & 6.76 & 0.75 \\
\hline UBC-846 & (CA)8RT & 11 & 10 & 91 & 3.76 & 0.376 & 7.45 & 2.81 & 5.52 & 0.79 \\
\hline UBC-855 & (AC) $8 Y T$ & 12 & 10 & 83 & 4.58 & 0.458 & 9.58 & 4.39 & 7.62 & 0.68 \\
\hline UBC-856 & (GGAGA)3 & 13 & 12 & 92 & 5.42 & 0.452 & 8.77 & 3.96 & 8.86 & 0.77 \\
\hline UBC-873 & $(\mathrm{GACA}) 4$ & 13 & 11 & 85 & 4.55 & 0.414 & 7.16 & 2.96 & 7.05 & 0.80 \\
\hline UBC-887 & $\mathrm{DVD}(\mathrm{TC}) 7$ & 12 & 11 & 92 & 4.97 & 0.452 & 8.84 & 3.99 & 8.10 & 0.77 \\
\hline \multirow{2}{*}{ ISSR } & Sub-Total & 98 & 85 & - & - & - & - & - & - & - \\
\hline & Avg./primer & 12.25 & 10.63 & 86.73 & 4.60 & 0.432 & 8.49 & 3.69 & 7.41 & 0.75 \\
\hline P13 & CCT GGG TGG A & 15 & 14 & 93 & 6.14 & 0.439 & 11.00 & 4.83 & 9.52 & 0.66 \\
\hline P21 & ACC GGG TTT C & 14 & 13 & 93 & 5.59 & 0.430 & 7.22 & 3.10 & 8.95 & 0.84 \\
\hline P31 & CCG GCC TTC C & 16 & 14 & 88 & 5.65 & 0.404 & 8.06 & 3.25 & 9.05 & 0.76 \\
\hline $\mathrm{P} 40$ & TTA CCT GGG C & 12 & 12 & 100 & 5.34 & 0.445 & 10.33 & 4.60 & 8.67 & 0.73 \\
\hline P42 & TTA ACC CGG C & 11 & 11 & 100 & 4.18 & 0.380 & 8.45 & 3.21 & 6.19 & 0.79 \\
\hline P46 & TTA AGG GGG C & 10 & 10 & 100 & 3.76 & 0.376 & 9.70 & 3.65 & 5.33 & 0.73 \\
\hline P47 & TTC CCC AAG C & 9 & 9 & 100 & 3.55 & 0.394 & 9.33 & 3.68 & 5.43 & 0.75 \\
\hline P54 & GTC CCA GAG C & 16 & 16 & 100 & 6.71 & 0.420 & 7.81 & 3.28 & 10.67 & 0.83 \\
\hline P62 & TTC CCC GTC G & 9 & 9 & 100 & 3.76 & 0.417 & 10.00 & 4.17 & 6.00 & 0.73 \\
\hline P77 & GAG CAC CAG G & 14 & 11 & 79 & 4.30 & 0.391 & 5.78 & 2.26 & 6.86 & 0.84 \\
\hline P78 & GAG CAC TAG C & 15 & 14 & 93 & 5.79 & 0.413 & 7.56 & 3.12 & 9.14 & 0.82 \\
\hline P81 & GAG CAC GGG G & 11 & 9 & 82 & 3.95 & 0.438 & 7.00 & 3.07 & 6.38 & 0.81 \\
\hline P84 & GGG CGC GAG T & 10 & 9 & 90 & 3.80 & 0.422 & 4.69 & 1.98 & 6.19 & 0.68 \\
\hline P86 & GGG GGG AAG G & 12 & 12 & 100 & 4.58 & 0.382 & 6.58 & 2.51 & 6.86 & 0.88 \\
\hline P95 & GGG GGG TTG G & 8 & 8 & 100 & 3.79 & 0.474 & 11.50 & 5.45 & 6.38 & 0.69 \\
\hline \multirow{2}{*}{ RAPD } & Sub-Total & 182 & 171 & - & - & - & - & - & - & - \\
\hline & Avg./primer & 12.13 & 11.4 & 93.96 & 4.73 & 0.415 & 8.33 & 3.48 & 7.44 & 0.77 \\
\hline \multicolumn{2}{|c|}{ ISSR + RAPD } & 280 & 256 & 91.43 & 4.67 & 0.423 & 8.41 & 3.59 & 7.43 & 0.76 \\
\hline
\end{tabular}

Note: TB - the number of total bands, PB: the number of polymorphic bands, PB (\%): the percentage of polymorphic bands, EMR: effective multiplex ratio, PI: polymorphism index, PIC: polymorphic information content, MI: marker index, RP: resolving power of primer, SI: Simpson's index 


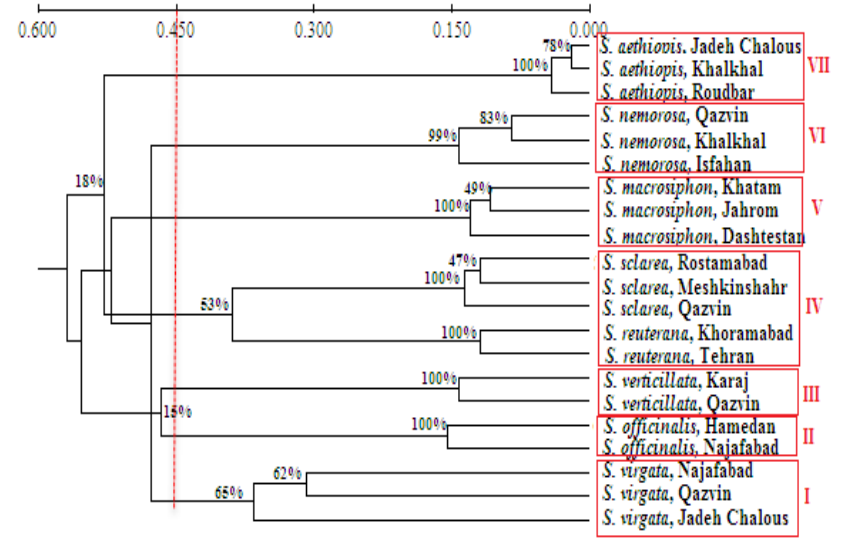

Fig. 1. Dendrogram of Salvia ecotypes based on Nei's genetic distance obtained from ISSR markers using the UPGMA algorithm. Numbers on branches refer to bootstrap values (1,000 replications)

results of AMOVA analysis showed that $68 \%$ of variance occurred among populations, and $32 \%$ variance occurred within populations. The similarity matrix revealed that Nei's similarity index ranged from 0.48 (among $S$. virgata, Najafabad and $S$. reuterana, Tehran) to 0.98 (between Chalous and Khalkhal ecotypes of $S$. aethiopis) with mean value of 0.61 (Data not shown). The UPGMA clustering algorithm for ISSR data based on Nei's genetic distances grouped 21 Salvia ecotypes, into seven groups at an average cutoff value of 0.45 (Fig. 1). Bootstrapping values demonstrated the confidence of tree topology and cutoff point was considered based on the confidence values more than 0.50 . It was concluded that the ecotypes from each Salvia species were grouped together into subclusters. Cluster I has three ecotypes, all from the $S$. virgata. Cluster II and III have four ecotypes belonged to $S$. officinalis and $S$. verticillata., respectively. Cluster IV includes $S$. reuterana and $S$. sclarea ecotypes. Cluster V, VI and VII grouped separately the ecotypes of $S$. macrosiphon, S. nemorosa and S. aethiopis, respectively (Fig. 1).

\section{RAPD analysis}

For RAPD analysis, 182 loci were produced by 15 RAPDs ranging from 300 to $3000 \mathrm{bp}$. Of which, 171 loci (93.9\%) were polymorphic (Fig. 3-b, Table 2). The number of TB detected with RAPDs ranged from eight (P95) to 16 (P31 and P54) with an average of 12.1 loci per primer. The number of $\mathrm{PB}$ was eight (P95) to 16 (P54) with an average of 11.40 polymorphic loci per primer. The percentage of polymorphism (PB\%) varied from 79 $\%$ for P77 to $100 \%$ for primers P40, P42, P46, P47, P54, P62, P86 and P95 (Table 2). P95 showed the highest PIC value (0.47) and P46 gave the lowest (0.38) with an average PIC of 0.415. Also, the highest EMR (11.5) was observed by primer P95, and the lowest was detected by the primer P84 (4.7) with an average of 8.3 per primer. The highest value of $\mathrm{MI}$ was devoted to primer P95 as 5.45 and the lowest MI observed in the primer P84 as 1.98 with an average of 3.48. The maximum RP belonged to primer P54 (10.7) and the lowest RP observed by P46 as 5.33 with an average of 7.4 per primer. Also, the highest value of Simpson's index (SI = 0.88) was observed in P86 and the lowest value, in P13 as 0.66 (Table 2). The Nei's gene diversity (h) and Shannon index (I) among all studied ecotypes of Salvia for RAPD data were calculated as $0.38 \pm 0.14$ and $0.55 \pm 0.18$, respectively. Mean coefficient of gene differentiation $\left(\mathrm{G}_{\mathrm{st}}\right)$ was

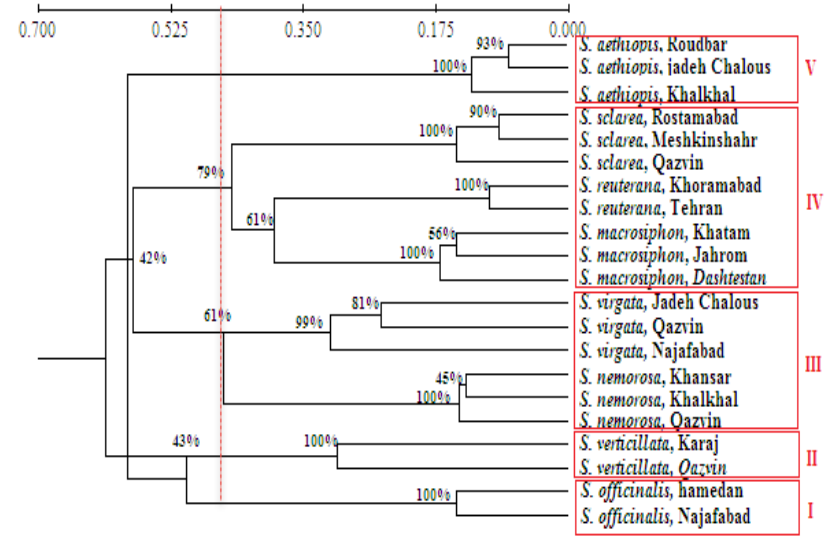

Fig. 2. Dendrogram of Salvia ecotypes based on Nei's genetic distance obtained from RAPD markers using the UPGMA algorithm. Numbers on branches refer to bootstrap values (1,000 replications)

found as 0.78 ; while the estimation of gene flow $\left(\mathrm{N}_{\mathrm{m}}\right)$ in the population was 0.14 (Table 3 ). The results of AMOVA analysis showed that $64 \%$ and $36 \%$ variance occurred among and within species, respectively. The similarity matrix indicated that Nei's similarity index ranged from 0.48 (between $S$. aethiopis, Khalkhal and S. sclarea, Meshkinshahr) to 0.92 (between ecotypes Roudbar and Chalous of $S$. aethiopis) with mean value of 0.59 (Data not shown). The UPGMA clustering algorithm for RAPD data classified 21 Salvia ecotypes into five groups at cutoff value of 0.45 (Fig. 2). As ISSR dendrogram, it was concluded that the ecotypes from each Salvia species were placed together into subclusters. Cluster I and II each has two ecotypes from $S$. officinalis and $S$. verticillata, respectively. Cluster III includes $S$. nemorosa and $S$. virgata each with their evaluated ecotypes. Cluster IV has $S$. macrosiphon, $S$. reuterana and $S$. sclarea ecotypes. Cluster V shows the ecotypes of $S$. aethiopis (Fig. 2).

\section{RAPD and ISSR-based combined analysis}

A total of 23 primers showed $91.4 \%$ polymorphism across all the ecotypes of Salvia. The mean values of PIC, EMR, MI, $\mathrm{RP}$ and SI observed for all the studied primers were $0.42,8.41$, $3.59,7.43,0.76$, respectively (Table 2 ). Based on combined data from ISSR and RAPD, the minimum genetic similarity (0.50) was observed between $S$. sclarea, Qazvin and $S$. officinalis, Najafabad; while the maximum of this coefficient (0.93) was recorded between ecotypes Roudbar and Chalous of $S$. aethiopis (data not shown). The Mantel correlation coefficient (r) between the Nei's genetic similarity matrices of ISSRs and RAPDs was high $(r=0.82)$. The results of species clustering based on UPGMA algorithm and Nei's similarity coefficients of combined data (ISSR and RAPD) at an average cutoff value of 0.45 determined three major groups, including $S$. aethiopis as the first group, $S$. officinalis and $S$. verticillata as the second group and five other species as the third group that has two subclusters $S$. macrosiphon, $S$. sclarea and $S$. reuterana in the first sub-cluster as well as $S$. nemorosa and $S$. virgata in the second sub-cluster (Fig. 5). Principal Coordinate Analysis (PCoA) was performed to provide spatial diagram of the relative genetic distances among ecotypes. PCoA revealed that the first three principal coordinate components accounted for $42.7 \%$ variation of the genetic similarity. In accordance to cluster 
Table 3. Summary of various genetic diversity indices analyzed in Salvia ecotypes

\begin{tabular}{cccccccccc}
\hline \multicolumn{2}{c}{ Diversity indices } & $\mathrm{N}_{\mathrm{o}}$ & $\mathrm{N}_{\mathrm{e}}$ & $\mathrm{h}$ & $\mathrm{I}$ & $\mathrm{H}_{\mathrm{t}}$ & $\mathrm{H}_{\mathrm{s}}$ & $\mathrm{G}_{\mathrm{st}}$ & $\mathrm{N}_{\mathrm{m}}$ \\
\hline Mean value \pm std. & ISSR & $1.87 \pm 0.34$ & $1.67 \pm 0.33$ & $0.37 \pm 0.16$ & $0.53 \pm 0.22$ & $0.37 \pm 0.03$ & $0.072 \pm 0.004$ & 0.804 & 0.122 \\
deviation & RAPD & $1.94 \pm 0.24$ & $1.67 \pm 0.30$ & $0.38 \pm 0.14$ & $0.55 \pm 0.18$ & $0.38 \pm 0.02$ & $0.082 \pm 0.005$ & 0.785 & 0.137 \\
\hline
\end{tabular}

Note: $\mathrm{N}_{\mathrm{o}}$ : observed number of alleles, $\mathrm{N}_{\mathrm{e}}$ expected number of alleles, h: Nei’s gene diversity, I: Shannon's information index, $\mathrm{H}_{\mathrm{t}}$ : heterozygosity, $\mathrm{H}_{\mathrm{s}}$ average heterozygosity, $\mathrm{G}_{\mathrm{s}:}$ degree of genetic differentiation, $\mathrm{N}_{\mathrm{m}}$ : estimate of gene flow
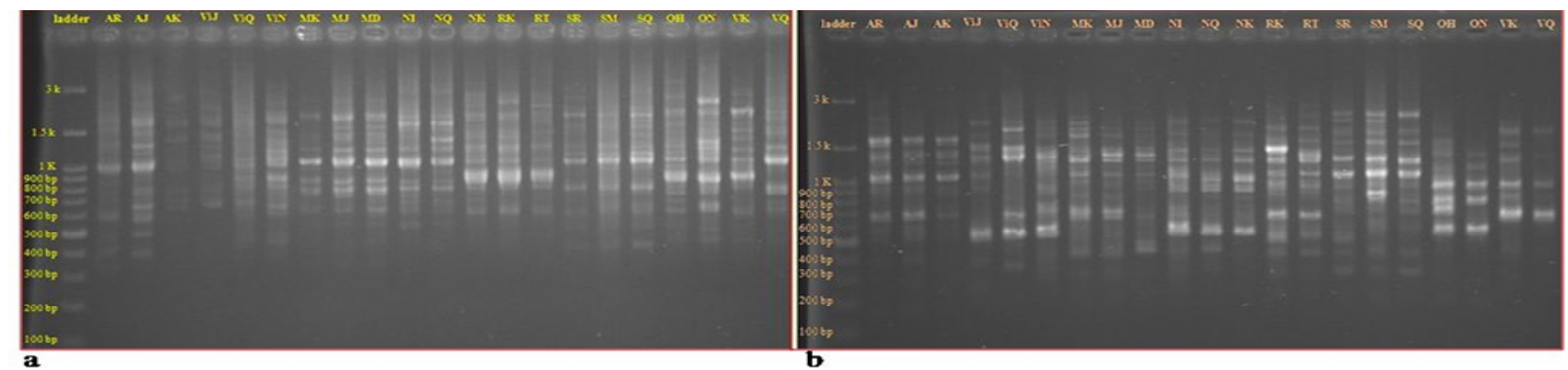

Fig. 3. ISSR (a, Primer UCB-873) and RAPD (b, Primer P13) markers pattern for Salvia species, respectively. DNA Ladder 100-3000 bp (DM2300-SMOBiO). Abbreviations of each ecotype are as listed in Table 1

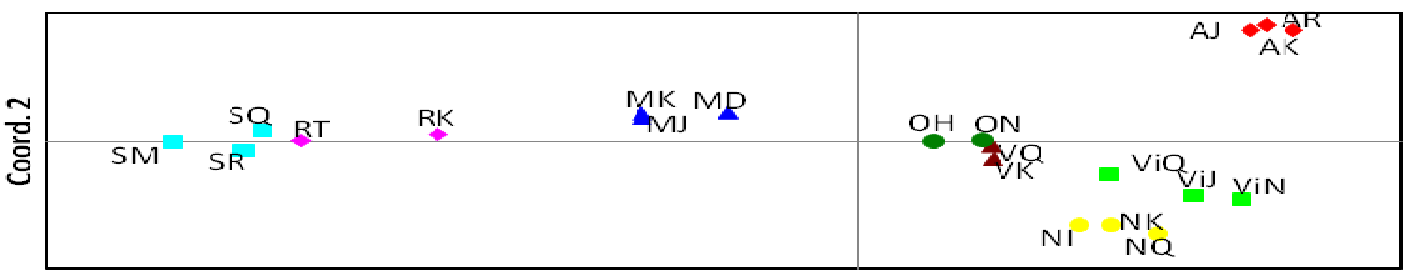

$$
\begin{aligned}
& \text { - aethiopis } \\
& \text { - virgata } \\
& \text { A macrosiphon } \\
& \text { nemorosa } \\
& \text { - reuterana } \\
& \text { sclarea }
\end{aligned}
$$

Fig. 4. A two-dimensional plot of the Principal Coordinate Analysis (PCoA) for ISSR and RAPD combined data showing the assortment of Salvia ecotypes. The first and second principal coordinates account for $15.6 \%$ and $15.5 \%$ of total variation, respectively. Abbreviations of each ecotype are as listed in Table 1

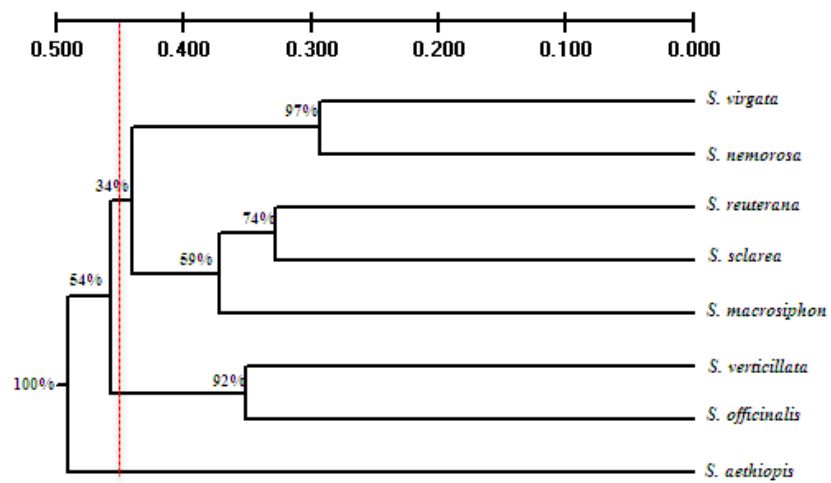

Fig. 5. Nei's similarity dendrogram of eight Salvia species generated by UPGMA algorithm based on combined data (ISSR and RAPD). Numbers on branches refer to bootstrap values (1,000 replications)

analysis, the ecotypes of the species were somewhat close to each other with the exception of two species, $S$. nemorosa and $S$. virgata; that are far from species $S$. macrosiphon, $S$. reuterana and $S$. sclarea. The three latter species were in the sub-clusters of third class in cluster analysis (Figs. 4 and 5).

\section{Discussion}

Most medicinal plants like Salvia have originated from wild herbs, so information on their genetic characters is essential for their domestication and conservation. Factors like reproductive systems, seed dispersal mechanism, and transferring to other regions are of the most important agents for genetic diversity of plant. The limitations of morphological studies can be overcome through the utilization of molecular markers (Zhang et al., 2013). DNA profiling methods used in this research contain regions of genome with substantially different evolutionary background. In the present study, of the eight ISSR and 15 RAPD tested primers, about 12 bands were averagely generated; RAPD markers had more polymorphic bands as 11.4 (93.9\%). Since the RAPD markers usually represent widely distributed portions of the genome and the ISSR profiles are produced from its microsatelliterich regions, this high polymorphism is expected. The similar results reported in Salvia miltiorrbiza based on ISSRs (Zhang et al., 2013) and other Salvia species using AFLP markers (Sajadi et al., 2010) as 95\% and 99\% polymorphism, respectively. Also, polymorphism index (PI) in RAPD primers was higher; whereas, other indices like PIC, EMR and MI were somewhat high in ISSRs. On the other hand, RP index was approximately equal in both techniques. In general, small differences in terms of calculated indices showed that both techniques had similar efficiency to differentiate the closely related ecotypes of Salvia. Chen et al. (2013) reported PIC values about 0.20 in ocimum species by ISSR and RAPD markers and also showed the RP values as 1.39 and 5.13, respectively. PIC analysis can be used to select the most appropriate markers for genetic mapping. Also, the high MI reflects the marker efficiency to simultaneously analyze a large number of bands (Powell et al., 1996; Patel et al., 2014). The high average Simpson's coefficients (about 0.80) indicate high genetic variability among studied accessions of Salvia, too. This finding was similar to the study by Manica-Cattani et al. (2009) on 
436

accessions of Lippia alba by ISSR and RAPD. In their study on Salvia lachnostachys ecotypes by ISSR primers, Erbano et al. (2015) showed a range of $0.66-0.86$ for Simpson's index.

Comparison of Nei's similarity coefficients between ISSRs and RAPDs showed that both markers had high diagnostic capability. This is consistent with the results of ISSR markers in Mint accessions by Kang et al. (2013) and Salvia miltiorrbiza germplasms studied by Zhang et al. (2013); while the genetic similarity derived from SRAPs and ISSRs represented high proximity among Salvia miltiorrhiza populations (Song et al., 2010). Cluster analysis could group all 21 ecotypes and the results showed reasonable congruency in RAPD and ISSR in terms of species topology. Zhang et al. (2013) showed five major clusters for S. miltiorrbiza germplasms based on Nei's similarity coefficient for ISSRs; which did not indicate any clear pattern according to their locations. Patel et al. (2014) reported that in dendrograms of ISSR and RAPD, the genotypes of each Ocimum species were grouped, separately.

Based on species phylogenetic clustering, it can be concluded that the species located in the common group may have closer genetic relationships. Nearby, populations of genus Salvia pollinated by bees may share many alleles and have gene flow; leading to genetic similarity of such species. Sepehri Javan $e t$ al. (2012) illustrated $S$. hydrangea and S. nemorosa as the most divergent species and good candidates for breeding programs. In the present study, S. aethiopis can be considered a divergent species.

The high Mantel correlation between two studied techniques was confirmed by Ma et al. (2012); Patel et al. (2014). So, there could be positive coincidence for ISSR- and RAPD-based similarities in Salvia. This high correlation has been reported between ISSRs and SRAPs in Salvia miltiorrbiza, too (Song et al., 2010; Peng et al.,2014).

\section{Conclusions}

The present experiment would provide useful genetic information for developing conservation strategies and domestication of Salvia species and ecotypes. The results showed that both studied techniques could separate species well via their ecotypes.

\section{References}

Chen SY, Dai TX, Chang YT, WangSS, Ou SL, Chuang WL, ChengCY, Lin YH, Lin LY, Ku HM (2013). Genetic diversity among Ocimum species based on ISSR, RAPD and SRAP markers. Australian Journal of CropScience 7(10):1463-1471.

Erbano M, Schühli GS, Santos ÉP (2015). Genetic Variability and Population Structure of Salvia lachnostachys: Implications for Breeding and Conservation Programs. International Journal of Molecular Sciences 16(4):7839-7850.

Kang MJ, Sundan S, Lee GA, Ko HC, ChungJW, Huh YC, GwagJG, Oh SJ, Kim YG, Cho GT (2013). Genetic Diversity and Population Structure of Korean Mint Agastache rugosa (Fisch \& Meyer) Kuntze (Lamiaceae) Using ISSR Markers. Korean Journal of Plant Resources 26(3):362-369.
Kharazian N, Rahimi S, Shiran B (2015). Genetic diversity and morphological variability of fifteen Stachys (Lamiaceae) species from Iran using morphological and ISSR molecular markers. Biologia 70(4):438452.

Liu J, Shi S, Chang E, Yang W, Jiang Z (2013). Genetic diversity of the critically endangered Thuja sutchuenensis revealed by ISSR markers and the implications for conservation. International Journal of Molecular Sciences 14:14860-14871.

Ma X, Chen SY, Bai SQ, Zhang XQ, Li DX, Zhang CB, Yan JJ (2012). RAPD analysis of genetic diversity and population structure of Elymus sibiricus (Poaceae) native to the southeastern Qinghai-Tibet Plateau, China. Genetics and Molecular Research 11(3):2708-2718.

Manica-Cattani MF, Zacaria J., Pauletti G, Atti-Serafii L, Echeverrigaray S (2009). Genetic variation among South Brazilian accessions of Lippia alba Mill. (Verbenaceae) detected by ISSR and RAPD markers. Brazilian Journal of Biology 69(2):375-380.

Nei M (1978). Estimation of average heterozygosity and genetic distance from a small number of individuals. Genetics 89:583-590.

Patel HK, Fougat RS, Kumar S, Mistry JG, Kumar M (2014). Detection of genetic variation in Ocimum species using RAPD and ISSR markers. 3 Biotech 5(5):697-707.

Peng L, Ru M, Wang B, Wang Y, Li B, Yu J, Liang Z (2014). Genetic diversity assessment of a germplasm collection of Salvia miltiornhiza Bunge. based on morphology, ISSR and SRAP markers. Biochemical Systematics and Ecology 55:8492.

Powell W, Morgante M, Andre C, Hanafey M, Vogel J, Tingey S, Rafalski A (1996). The comparison of RFLP, RAPD, AFLP and SSR (microsatellite) markers for germplasm analysis. Molecular Breeding 2(3):225-238.

Rizza MD, Real D, Reyno R, Porro V, BurguenoJ,Errico E, Quesenberry KH (2007). Genetic diversity andDNA content of threeSouth American and three Eurasiatic Trifolium species. Genetics and Molecular Biology 30(4): 1118-1124.

Sajadi SS, Shiran B, Kharazian N, Houshmand S, Sorkheh K (2010). Genetic diversity of Saluria species from Chaharmahal va Bakhtiari and Isfahan province using AFLP molecular markers. Iranian Journal of Horticultural Sciences 40:79-88.

Sepehry Javan Z, Rahmani F, Heidari R (2012). Assessment of genetic variation of genus Salvia by RAPD and ISSR markers. Australian Journal of CropScience 6(6):1068-1073.

Song Z, Li X, Wang H, Wang J (2010). Genetic diversity and population structure of Salvia miltiorrbiza Bge in China revealed by ISSR and SRAP.Genetica 138(2):241-249.

Wang M, Li J, Zhang L, Yang RW, Ding CB, Zhou YH, Yin ZQ (2011). Genetic diversity among Salvia miltiorrhiza Bunge and related species using morphological traits and RAPD markers. Journal of Medicinal Plants Research 5(13):2687-2694.

Zhang Y, Li X, Wang Z (2013). Diversity evaluation of Salvia miltiorrbiza usingISSR markers. Biochemical Genetics 51(9):707-721. 